\title{
A viagem de Oribela em Desmundo
}

\section{Pricila Reis Franz*}

\begin{abstract}
Resumo: O presente artigo objetiva analisar a temática Abstract: this essay analyzes the theme of traveling in "viagem" na obra Desmundo de Ana Miranda, as Desmundo, by Ana Miranda. It shows the alterações, a busca de identidade, o choque de Oribela modifications, the search for identity, the shock and the (órfã que faz viagem forçada para o Brasil), bem como interchange of cultural aspects between the character as trocas de aspectos culturais que ocorrem entre esta e Oribela (an orphan who travels by force to Brazil) and "o outro, o novo", representado nas figuras do mouro "the other, the new", represented by Ximeno Dias, by Ximeno Dias, dos naturais brasileiros e da comunidade the Brazilian natives and by the Portuguese community portuguesa existente no Brasil Colônia. Será existent in colonial Brazil. Also, it explains the external apresentada também a viagem exterior e interior da and inner travel of the protagonist, demonstrating all protagonista, demonstrando sua visão sobre o her point of view about Desmundo (Brazil), with all the Desmundo (o Brasil), com todas as lendas e crendices legends and convictions typical of the Christianpróprias da concepção cristã portuguesa do Novo Portuguese view of the New World.
\end{abstract}

Mundo.

Palavras-chave: viagem; alteridade; colonização. Keywords: travel; alterity; colonization.

O presente ensaio busca analisar a temática "viagem" na obra Desmundo (1996), de Ana Miranda. A história narra a viagem forçada de Oribela que, juntamente com outras órfãs, é enviada de Portugal para o Brasil no século XVI, com o intuito de se tornar esposa dos portugueses residentes na Colônia, pois estes estavam se relacionando com as índias e desviando-se do caminho cristão. Embora haja alguma fortuna crítica sobre esta obra ${ }^{1}$, nenhuma se dispõe a analisá-la sob este prisma original, a temática da viagem.

\footnotetext{
Tradutora e mestra em Literatura Portuguesa, Brasileira e Luso-Africanas (UFRGS). Site pessoal: http://www.pribi.com.br . E-mail: pricila@pribi.com.br.

${ }^{1}$ Dissertações: JABOUR, Luciana. (RE) CONTANDO A HISTÓRIA: ficção e história no Desmundo de Ana Miranda. Juiz de Fora: CESJF, 2006. Disponível em: http://www.cesjf.br/cesjf/Noticias/pdfs/Editais_Dissetra\%C3\%A7\%C3\%A3o/DISSERTA-

Luciana\%20Jabour.pdf; GOMES, Cláudia Espíndola; ALMEIDA, Tereza Virginia de. UNIVERSIDADE FEDERAL DE SANTA CATARINA Centro de Comunicação e Expressão. Oribela o uno que se desdobra. Florianópolis: UFSC, 2000. 91 f. Dissertação (Mestrado). Artigos: SÁ, Jussara de; FERNANDES, Liomar. O desejo e o interdito no Desmundo: (in) possíveis entrelaçamentos. In: Revista Querubim, Ano 4, n. 6, 2008. Disponível em:

http://www.revistaquerubim.com/O desejo e o interdito no Desmundo (in) poss\%EDveis entrela\%E7amentos Jussara Bittencourt de S\%E1 e Liomar Vanderlan Fernandes.doc; SCHMIDT, Simone. Desmundo, Desmando, Desencanto. In: Portuguese Cultural Studies, Volume One. Disponível em: http://www2.let.uu.nl/solis/psc/P/PVOLUMEONEPAPERS/P1SCHMIDT.pdf
} 
A obra apresenta a viagem exterior e interior da protagonista, demonstrando toda a sua visão sobre o Desmundo, isto é, o Brasil, com todas as lendas e crendices próprias da concepção cristã portuguesa do Novo Mundo. Mostra o choque e a transformação que a órfã sofre ao ser confrontada com a nova realidade, terras e outras culturas, aproximando-se e identificando-se com outros povos e grupos, como índios e mouros que, como ela, são marginalizados na cultura colonizadora. Como característica dessa literatura de viagem (isto é, com a temática viagem na literatura) observa-se que "é a manifestação do outro que leva, a posteriori, à indagação e reconstituição da identidade própria..." (SEIXO, 1998, p. 37). Ou seja, é através dessa travessia (interior e exterior), que Oribela se encontra e descobre seu lugar no mundo, sua realização.

Em primeiro lugar, faz-se necessário situar a obra no contexto histórico-literário brasileiro. Ana Miranda pertence a uma geração de autores reconhecidos por sua metaficção historiográfica, ou seja, seus livros geralmente partem de um personagem ou fato histórico que são fundidos, introduzidos na obra ficcional, a fim dar um valor de legitimidade à ficção. A metaficção historiográfica surgiu após a ditadura militar, desmantelando a história até então tida como "oficial, verdadeira", para apresentar os fatos por outros ângulos, reconstruindo a visão das minorias, dos vencidos, de maneira fragmentária. Não possuem a ilusão de serem a única versão da realidade, de reconstruir ilusões perdidas, mas buscam recuperar do passado alguns fragmentos que possuam lacunas que possam ser preenchidas, re-inventadas, redimindo-os ou perturbando-os na sua tranqüilidade. O romance afasta o olhar do presente e se volta para o passado, a fim de identificar lendas e traços característicos que auxiliem na busca de identidade atual e desconfiem das utopias e dos mitos gerados pelo progresso. A metaficção histórica não pode ser confundida com o romance alegórico-documental existente nos tempos da ditadura que buscavam mostrar a verdade, pois o que os romances históricos modernos buscam questionar é de quem é a verdade que se conta.

No caso de Desmundo (1996), a narrativa tem como ponto de partida uma carta real datada de 1552 de Manoel de Nóbrega a D. João, solicitando o envio de mulheres portuguesas para se casarem com os colonizadores no Brasil. Esse fato também pode ser comprovado pelos estudos feitos na obra Ao Sul do Corpo (1993), em que foi constatada, através de registros e documentos, a política da Igreja de criar no Brasil a sociedade cristã perfeita, uma espécie de Paraíso brasileiro, onde a mulher era escrava doméstica do homem e seu adestramento fazia parte do processo civilizatório, a serviço da colonização:

A Igreja apropriou-se também da mentalidade androcêntrica presente no caráter colonial e explorou as relações de dominação que presidiam o encontro de homem e mulher, 
incentivando a última a ser exemplarmente obediente e submissa. A relação de poder já implícita no escravismo reproduzia-se nas relações mais íntimas entre marido e mulher, condenando esta a ser uma escrava doméstica, cuja existência se justificasse em cuidar da casa, cozinhar, lavar a roupa, servir ao chefe da família com o seu sexo, dando-lhe filhos que assegurassem a sua descendência e servindo como modelo para a sociedade familiar com que sonhava a Igreja. (DEL PRIORE, 1993, p. 29)

A autora então decide narrar a trajetória dessas primeiras mulheres, em especial, de Oribela (nome proveniente da árvore oliveira), uma personagem que, desde o início, apresenta um caráter rebelde e determinado. É sonhadora e possui, num primeiro momento, uma forte visão cristã do Novo Mundo, mas que vai sendo transformada através da convivência com outros tipos de cultura, com a amizade e troca de experiências com as índias, e culminando na realização da paixão sentida desde o primeiro encontro, pelo mouro Ximeno Dias (situação inicialmente relacionada à tentação, ao demônio).

Inicialmente, Oribela faz essa viagem forçada, pois, embora tenha raízes fortes em sua terra natal (Portugal), não é dona de seu destino; é uma órfã, mas, ao mesmo tempo, deseja uma vida nova, que é proporcionada pelo mar pelo qual fica "escrava", desejosa de viajar:

\begin{abstract}
... distante de onde fora eu arrancada com muita pena por serem meus pés quais umas abóboras nascidas no chão, minhas mãos uns galhos que se vão à terra e a agarram por baixo das pedras fundas. Aquele era o meu destino, não poder demandar de minha sorte, ser lançada [...] até o fim do mundo, que para mim parecia o começo de tudo, era a distância, a manhã, a noite, o tempo que passava e não passava, a viagem infernal feita dos olhos das outras órfãs que me viam e descobriam, de meus enjôos, das náuseas alheias, da cor do mar e seu mistério maior que o mundo. O mar [...] nos deixa feridos de morte e de amor. O mar nos deixa seus escravos, mar que não se pode tomar porto e se fica sendo dele inteiramente. (MIRANDA, 1996, p. 15)
\end{abstract}

Assim como a protagonista, as órfãs deparam-se na travessia do mar com a vida e a morte (ao falecer D. Izobel, a sétima órfã). Essa viagem (exterior e interior) sem escolha permite Oribela a buscar e a questionar sua identidade, suas convicções e seu sentido de vida. Mesmo sem poder decidir seu destino, essa viagem gera uma expectativa na órfã, pois toda a travessia "se fundamenta numa expectativa, e por isso ela é sempre corrente" (SEIXO, 1998, p. 30-31). Nesse caso, a expectativa é incógnita, que Seixo afirma que é a mais própria da viagem. Oribela não sabe o que a espera, apenas conhece a colônia por lendas e crendices com as quais lhe instruíram. Contudo, tem esperança de ter uma vida boa e feliz no Brasil, o que só é obtido no final, depois do despojamento de seus valores cristãos portugueses e da abertura a novos conhecimentos e sentimentos através da luta por sua felicidade.

A idéia de Oribela sobre o Desmundo está baseada em várias crenças e lendas, como a do Paraíso Perdido, com suas bestas e feras. Essas crenças fazem parte do coletivo medieval português que ela carrega consigo. Segundo IANNI: “o caminhante não é apenas um 'eu' em busca do 'outro'. Com freqüência é um 'nós' em busca dos 'outros'. Há sempre algo de 
coletivo no movimento da travessia, nas inquietações, descobertas [...] dos que se encontram, [...] conflitam, mesclam..." (1990, p. 16). É interessante observar a passagem em que Oribela, ouvindo os marujos do navio, descreve a crença portuguesa de que a Terra acabava num ponto em que se podia cair no abismo, ao passar pelo lado debaixo. Isto só não acontecia apenas por causa de uma cerca feita pela misericórdia. E a comprovação dessa crença havia se dado através da frota saída de San Lúcar que teria ido por um lado e voltado por outro.

A seguir percebe-se então a primeira visão de Oribela do Brasil, já no início do livro, em que descreve a paisagem verde, a chuva de inverno e alguma alegria no coração:

A vista de uma colina distante tangeu dentro do meu coração música de boas falas, com doçainas e violas d'arco, a ventura mais escondida clareia a alma. Ali estava bem na frente a terra do Brasil, eu a via pelos estores treliçados, lustrada pelo sol que deitava. Uxtix, uxte, xulo, cá! Verdadeira? Tão pequena quanto pudesse eu imaginar, lavada por uma chuva de inverno, verde umas palmeiras altas no sopé, por detrás de nuvens de tapeçaria, véu de leve fumo. Hio, hio, huhá. Espantada que a alegria. (MIRANDA, 1996, p. 11)

O Brasil é também conhecido como o mito de El Dourado, lenda que Oribela ouve em Portugal; segundo a lenda, existem na colônia animais fantásticos e todo mundo vive mais de trezentos anos, felizes, sem dores, angústias, tristezas ou fome. "Há homens de cauda, que andam de quatro." (Ibidem, p. 39). Ainda afirma que não há mulheres (o que não deixa de ser fiel à mentalidade dos portugueses, visto que, para eles, os índios não possuíam alma) e as poucas que, por acaso, existem, têm poderes, podem realizar seus desejos e mandos, sendo tratadas como rainhas. Contudo, todas essas imagens fantásticas são desmentidas já nas suas primeiras impressões: “Agora sei do que estavam dizendo” (Ibidem, p. 39).

Ainda assim, a protagonista se sente esperançosa, pois nasce em seu coração a possibilidade de iniciar uma vida nova nesse mundo bonito, natural, nesta terra verde, de palmeiras e "onde nunca entrava o inverno” (Ibidem, p. 13). Sua visão é otimista: “... tudo parecia alta maravilha, [...] nova vida...” (Ibidem, p. 12), “... chegamos a um novo país com o coração em júbilo, mas de dúvida e receio, para povoar um despejado lugar" (Ibidem, p. 16).

À medida que Oribela aproxima-se da terra firme, vai confrontando suas primeiras impressões com as lendas que traz da cultura portuguesa:

Qué aqui? Umas povoações não fortificadas, não podendo resistir a afrontas, vivendo os moradores tão atemorizados que deixaram suas coisas metidas em sacos para correram ao mato à vista de qualquer vela, ou para o mar ao grito de um bugre, aldeias e vilas que mal se supunha onde se podia acabar, mais embaixo, um rio só de pratarias e de gente castelhana que se ajuntava a selvagens e correria mundo, matando, assacando, sem medo de abismos nem dos gigantes que lá viviam metidos em roupas de ciganos. (MIRANDA, 1996, p. 20)

A protagonista observa que a colônia existe apenas para a exploração de seus recursos, não há um planejamento efetivo para a permanência dos portugueses no Brasil 
(principalmente pelo fato de que os enviados para o novo mundo eram ladrões e pessoas condenadas pela sociedade portuguesa, ou aqueles que vinham provisoriamente aqui para enriquecer).

Confronta-se também com a comprovação da existência de seres só conhecidos por lendas em Portugal, como o papagaio, "ave verde que sabia falar palavras humanas, a qual conhecera eu por lenda, sendo esta mais pequena e mais aborrida." (Ibidem, p. 45)

Sua descrição da cidade demonstra um olhar estrangeiro, de quem estranha o que vê, uma imagem de ruína e luxúria da cidade (como se fosse velho o lugar) e uma grande admiração pela natureza local: palmeiras de frutos verdes, tâmaras, parreiras, laranjais em flor, tudo circundando a vila, espalhando "os cheiros de bom odor devestido e defumado de seu mau fedor..." (Ibidem, p. 36). Mas, mesmo com esses maus odores, a cidade não é triste, pois tem um ar de "festa profana, de colher frutos que se buscassem." (Ibidem, p. 46). A órfã fica impressionada com a fartura de verde existente no Brasil, com a frescura do arvoredo e com o clima, pois não há neve no alto das montanhas; no máximo, as neblinas que encobrem o alto das serras. Oribela fica tão maravilhada com a natureza que não sabe nem para onde olhar, se para as flores amarelas das árvores, para as florzinhas de canudos pequenos e tenros, para as águas liberais ou dos bosques; tudo é muito belo, tudo a encanta.

Com relação à civilização, é necessário destacar também a inversão de hierarquias na colônia, fato que chama a atenção de Oribela, pois todos agem como se fossem donos da terra e do seu "nariz", uma vez que a instituição reguladora (o rei e a rainha) não está presente, mas sim, muito distante. Além disso, muitos dos serviçais se vestiam melhores do que as órfãs, como se fosse fidalgos "num coche ao paço ou às Endoenças, alma a caminho do inferno, seu colo supunha jóias de ouro, margaridas, que são Jesus no colo das boas mulheres e pérolas no das putas e das regateiras.” (MIRANDA, 1996, p. 35)

Além de tudo o que vê, Oribela recebe instruções de quem já está na colônia há mais tempo, como por exemplo, a mulher do governador, que dá conselhos às órfãs e pinta a sociedade portuguesa colonial que vai recebê-las com cores agradáveis, vida fácil, sustentada pela escravidão:

\footnotetext{
... era o povo do lugar muito caridoso para dar e tinham suas cozinhas abertas aos padres na hora das refeições. [...] Mas que deitássemos na nossa boa fortuna, aqui nesta terra, quem fazia comida? [...] Quem cultivava horta? As naturais. As naturais, as naturais, que neste país os pobres vivam feito fidalgos de até cem escravos, o pobre mais miserável que fosse podia ter três escravos salteados, que os havia feito gravetos pelo mato, quem lhes apanhava as castanhas e lhes ia à lenha, fazia o lume, caçava, cultivava a horta? Aqui era mais preciso ter bons olhos do que boas mãos, para ver onde se deitava o marido, se em rede ou cama, se deitava as bugras e se as dormia, se as fazia parir, que fosse, mas lhes dar aroma e ouro em atavios, nunca. (MIRANDA, 1996, p. 44)
} 
Sua visão sobre a existência das naturais lança em Oribela dúvidas sobre as crenças que possuía da forma como tinham filhos no Brasil, fruto de mais uma crendice: "Nunca fora dito haver mulheres assim, nem pudera inventar em minhas ignorâncias. [...]. Quem então há de parir naquelas terras? Os machos, por ordem de Deus. E por onde? Afirmam que são essas crianças lançadas pelos sovacos, pelo do braço direito machos e pelo do esquerdo fêmeas." (Ibidem, p. 39)

Embora tenha vindo à força para o Brasil, a protagonista é uma jovem sonhadora e rebelde, que luta por sua felicidade, ainda que nem sempre tenha forças suficientes para isso, por sua condição de mulher. Isso já é demonstrado na escolha dos noivos para o casamento, quando Oribela cospe no seu candidato, rebelando-se e sendo severamente castigada: "Que besta tu és e de asas, feito uma galinha que quer avoar e não pode.” (Ibidem, p. 57).

A órfã admira a Velha, personagem responsável por tomar conta das órfãs e que possui alguma sabedoria, "estrelada pelos conheceres do mundo", sábia na religião, capaz de falar aos "mais mestrados dos homens", cercada de livros. Sabe que não é como ela, que não possui tal alteza, tal estatura, tal cabeça abençoada pelas luzes do conhecimento. Deseja então também ser sábia, mas, ao mesmo tempo, misteriosa, reclusa consigo mesma, numa certa forma de viagem, de busca interior de si mesma: "nem era eu a que me mostrava dia após noite, nem sabia muito eu mesma. [...] Que meu vencimento no mundo era ser mistério. Vivia eu metida dentro de mim para saber para onde endereçavam meus pensamentos [...], alcançar minha verdade, meus remansos, [...] saber como não entrarem em mim e me descobrirem." (Ibidem, p. 74)

Oribela age dessa forma rebelde com seu candidato ao matrimônio porque, assim que chegara ao Brasil, foi tomada de paixão, admiração e tentação por um mouro. A primeira visão que Oribela teve de Ximeno Dias, o mouro, arrebata-lhe o coração:

um homem de cavalo, vestido ricamente e com bota de cordovão, capa, sombreiro, seguido de seus escravos naturais com armas e mais uns negros de Guiné, tilintando de metais, cintilando raios e cheirando às peles manchadas que forravam os da terra, fez com que todos se afastassem a deixarem passar tal majestade, o cabelo de mecha da cor do cobre e uma grande quantidade pêlo no braço, sempre ruço, veio num modo de querer alevantar o rebuço e verificar, fôramos putas ou barbadas, trasgos, mandrágoras. (MIRANDA, 1996, p. 27).

A impressão que Oribela tem é de estar perante um príncipe. E o primeiro diálogo entre os dois se dá justamente pelo fato de Oribela estar usando os sapatos de Dona Izobel (macios de pele, atados por fitas de veludo preto), prometida de Ximeno que morrera na viagem. Já estavam predestinados ao amor. A órfã descalça os sapatos, leva-os ao homem que levanta seu véu e mira detalhadamente sua face "num segredo de seu pensamento" e, quando 
ele pergunta se era uma das órfãs do mosteiro, Oribela sente uma carência, uma fome de carinhos, mimos e afagos, sentindo-se mais uma vez desvalorizada. Contudo, ao ver o olhar triste, doce e manso do mouro, suspira "nas partes em que se semeia e se granjeia o sentimento, aquentada no meu frio, fartada na minha fome, em frescos jardins." O "príncipe" ordena que ela fique com os sapatos, "se me cabiam deviam ser meus e em joelho os meteu aos meus pés. Suas mãos tremiam, fosse embora bravo e destemido na sua maneira, o que lhe fez grande oposição." (Ibidem, p. 28) Observa-se, aqui, uma referência ao conto infantil da Cinderela, uma órfã abandonada, praticamente escrava doméstica, que é calçada pelo príncipe encantado. Seu suspiro e o tremor das mãos do mouro já denunciam os sentimentos que um tem pelo outro.

Contudo, ao saber que ele é um mouro, Oribela torna confusos seus sentimentos e convicções, num misto de tentação, pecado, amor, liberdade e reconhecimento de que ele também sofre preconceitos por pertencer a uma minoria, os desprezados da sociedade portuguesa: "Não contestou ele de ser mouro ou de não ser, de modo que provava ser, embora não fosse de cor maura nem levasse lua vermelha no ombro" (Ibidem, p. 29). A partir desse momento, a protagonista descreve detalhadamente todas as lendas, mitos, crendices e preconceitos que a sociedade portuguesa tem contra os mouros, afirmando que eram cegos e bestiais, acreditando nas virtudes do deleite da carne, na vingança contra os inimigos, na valentia e no direito dos homens terem muitas mulheres, fossem elas esposas, amantes ou escravas. Pensa que são mentirosos, que vivem em seus reinos uma vida costumeiramente pecaminosa. Oribela então procura fugir, retirar seu olhar das feições do mouro, a fim de não guardar nenhuma lembrança de uma alma "parida pelo Maomé”. Contudo, em seu coração o sentimento já brotou, a paixão pelo desconhecido já surgiu, juntamente com a tentação que a perseguirá durante toda a obra: "a vista dele se marcara, que dela me não podia livrar, [...] estava ele dentro de mim ardendo como um feiticeiro, os mais desumanos e cruéis inimigos nunca se viu no mundo." (Ibidem, p. 29)

Buscando esquecer a bela imagem que o mouro deixou em seu coração, Oribela passa a discorrer sobre mais algumas ofensas que os cristãos portugueses afirmavam dos mouros, chamando-os de almas frias, violentos, bravos, bélicos, esquivos, brutais, cruéis, que penduram pelos prisioneiros e lanceiam seus corações, ladrões, que levam suas filhas à luxúria, que são consumidos pelo fogo do inferno e por isso comem barro do chão para se refrescarem; adoradores do ouro, viciados em jogos, sedutores, feiticeiros, falsos, astutos e malvados, entre outras descrições. É necessário observar que o próprio conhecimento de astronomia que eles possuem é considerado obra demoníaca: 
... diziam ser o mar uma campina que ia dar nos nevoeiros e vapores do fim do mundo, conheciam os rumos do vento mas se deixavam ir pelas tentações marítimas e que quando se abriam ao capricho de alguém era para o tragar, feito fossem o próprio mar oceano, tenebrosas águas, numa irresistível tentação que os arrastava para a natureza, de dia a discorrer, de noite a interrogar junto aos demos, velados pelos mantos negros de seus mistérios, que sabiam navegar até sem agulha e sem balestilha, só por verem as estrelas e pelos ventos, por serem da mesma matéria das trevas do mar tão horrorosos em suas façanhas... (MIRANDA, 1996, p. 31)

E Oribela busca justificar sua boa impressão do Ximeno devido à feitiçaria, pois, mesmo que fosse de boa feição, "aquilo só encobria a verdade de sua maldade bruta, sua ferocidade, sua rudeza de animais selváticos, feito cafres e faziam a mulher parir sapo, fosse cristã." (Ibidem, p. 31). Contudo, a protagonista não consegue evitar sua paixão, tornando-se infeliz em seu casamento com um português. Por isso, sucumbe posteriormente à tentação do desconhecido, entregando-se ao mouro de corpo, mente (adquirindo novos conhecimentos) e alma. Por tudo isto, e pela sua condição de mulher, Oribela só consegue sua liberdade e felicidade ao final da história, quando vence seus preconceitos contra o mouro e obtém o amor correspondido.

Ao falar sobre a condição de mulher na colônia, é necessário verificar qual a visão que os portugueses tinham sobre as mulheres e essa era sempre preconceituosa e discriminadora, tornando-as seres inferiores. Já no início da viagem, as mulheres são descritas como mau agouro nos navios, pois são "baús cheios pedras muito grandes e pesados", não servem para ajudar no serviço marítimo; muito pelo contrário, até atrapalham, pois tiram a concentração dos marujos e só sabem reclamar sem motivo algum, só pelo prazer, "feito os demos." (Ibidem, p. 24). Essa visão diabólica da mulher não é fruto da imaginação da autora do romance, mas está registrada no estudo feito por DEL PRIORE (1993):

considerada também um 'diabo doméstico', ela fora pintada na literatura da época clássica como um poço de vícios digno dos filhos das trevas: enganadora, melíflua, concupiscente, fétida, infecta, gastadora, desbocada, esta mulher sem qualidades foi cantada em prosa e verso no período... (DEL PRIORE, 1993, p. 36)

Além disso, quando possuem algum valor, são consideradas apenas como um objeto de desejo ("leitoas para abate"), ou uma peça em que se fazem as crianças. Assim, as órfãs só são valorizadas na escolha dos noivos, numa espécie de leilão das noivas. Nesse momento, há uma supervalorização e elas são tratadas como rainhas, como se fossem de carne e alma, humanas, não mais tratadas como animais, seres inferiores, com serventia nos afazeres domésticos, tais como: lavar as roupas, manter acesos os fornos, trabalhar nos teares e com as agulhas, buscar água, fazer comida e também para o deleite da carne. E as órfãs, que eram de pele branca, cristãs (ou seja, preservando a identidade portuguesa cristã na colônia, sem 
miscigenação) tinham ainda um bem mais precioso que era a sua virgindade, considerado um bem (visto que eram órfãs e não tinha um dote em dinheiro). Com todos esses elogios, essa supervalorização diante de homens tão necessitados, Oribela celebra a cegueira destes e sentese orgulhosa, especial, como uma ninfa, uma jóia rara, uma fidalga ou até mesmo rainha, esperançosa de que não terá mais uma vida de sofrimentos, de trabalho duro ou situação econômica difícil.

Já no casamento das órfãs surge a dura realidade: Oribela casa-se com o português Francisco de Albuquerque e na noite de núpcias transparece novamente a condição de mulher apenas como objeto, sendo estuprada:

\begin{abstract}
Os homens se serviram de suas esposas. [...] Para deitar, um monte de feno, mas a mim foi segurando Francisco de Albuquerque e derrubando. É acaso a leoa mais mansa que o leão? E lhe dei uma bofetada no rosto no que fez ele sem pensar uns modos de como se fosse quebrar minha caveira, me fez tremer as carnes e o fervor dele, disto, era tão grande, em tal momento, que em muito breve espaço tudo meu estava como que em grilhões, entre suas forças, embaixo de seus pesos, a arrancar tudo que era seu e de Deus, cobrar sua repartição, seu quinhão que lhe valia por direito de esposo, como em mim havia de ser tudo seu, mas eu rogava que nada fosse tanto, entendendo de querer escapar de embaixo dele, de modo que se tinha dentes devia ser para cobrar as penas, quem deu foi pensando, assim foi Francisco de Albuquerque trabalhar sobre mim, recolher de minha boca o silêncio e a fechadura em sua boca. (MIRANDA, 1996, p. 76)
\end{abstract}

Após o casamento, Oribela passa a fazer outra viagem, para o interior do Brasil, cada vez mais dentro e distante do oceano. A recém-casada sente-se duplamente órfã e carente, pois agora, além de ter saudades e querer voltar para Portugal, sente falta do mar, de quem se tornou escrava. Enquanto viaja interiormente na sua saudade, vai descrevendo a paisagem que se modifica aos poucos: “... até se acabarem as ermidas e os engenhos, acima, uma volta, um esteio, uma enseada, sempre beirando rio, o rio do rio, que tornava eu sempre as vistas para trás, cada vez mais longe se metia a vila e cada vez mais triste estava eu." (MIRANDA, 1996, p. 81). O casal vai para as terras de Francisco, onde vivem sua mãe D. Branca (que sempre desconfia da rebeldia de Oribela), e sua filha-irmã (deficiente mental) Viliganda, resultado de incesto (bestialização da civilização), fato considerado natural pela falta de mulheres portuguesas: "filha frutificada do filho com a mãe, se assim fosse, eu a tomasse por minha menina e a amasse como fruto meu" (Ibidem, p. 133). A protagonista não aceita a condição que lhe é imposta, de viver cativa nestas terras, sem ter amor por seu rude esposo - que a ama e é bem menos violento que os maridos das outras órfãs -, e anseia por voltar ao mundo civilizado (Portugal), fazendo algumas tentativas de fuga, na esperança de conseguir entrar no navio de retorno a Lisboa.

Nesse tempo de adaptação nas terras de Francisco, é interessante observar a troca de 
cultura que ocorre entre a órfã e as naturais. A primeira visão que Oribela tem dos índios ainda na vila, antes do casamento chama sua atenção, primeiro pelo desvirtuamento dos padres que estão por aqui, já amancebados, já acostumados com os naturais; e, em segundo, pela sexualidade explícita dos índios:

E se as havia, mulheres naturais, até eram graciosas em seus despudores, florescidas, feito aves, de pés embicados para dentro como duas naus a abalroar e fedendo igualmente aos machos, por um tipo de óleo que se esfregavam, semelhando a podre, a estrume, a gruta e de quem diziam dar uma febre muito maligna se as fodessem nos dias de lua quando lhes havia sob os cabelos uns cornos pequeno. E vi um extravagante dentre eles, a se encostar numa libidinosa que lhe fez inchar a parte, tanto que parecia um bruto. (MIRANDA, 1996, p. 39)

Observa-se nesse trecho a visão que Oribela tem das naturais misturada com suas crenças portuguesas, tratando as índias como animais selvagens. Ela então lembra de Cham. Tantos os naturais como os negros eram considerados filhos de Cham. Na história bíblica, Cham era filho de Noé que foi castigado por não cobrir a nudez do pai quando este estava bêbado, condenando toda a sua descendência a andar nua e a servir os outros filhos Seth (pai dos pardos) e Japhet (pai dos brancos) e suas futuras gerações, numa clara justificativa cristã para a escravidão.

Contudo, nas terras de Francisco, parte desse preconceito é quebrado, quando o português deixa Oribela acorrentada (depois de fugir pela primeira vez) e sai mata adentro, por alguns dias. Nesse momento, ocorre uma troca cultural entre a órfã e as naturais, em especial, com a índia Temericô, desmitificando muitas das lendas que conheceu em Portugal e até aprendendo a língua indígena; ao mesmo tempo, Oribela narra histórias e lendas sobre Portugal para as índias: "As plantas não têm alma, as mulheres não têm barba, os passarinhos não têm leite, abá supé-pe oro-ikó-né? Muitas mais coisas me ensinou a natural de sua fala..." (MIRANDA, 1996, p. 127); histórias de fidalgas, rainhas e os costumes da corte portuguesa, "falava eu de minhas renembranças, do modo que alembrava na minha fantasia e se não, em falsidades, mas formosas, de seduzir meu coração partido”. (Ibidem, p. 123). Além disso, aprende os fumos das naturais que a deixam fora de si, pasmada e sonhadora, "quando na minha fantasia eu procurava o que não queria achar. [...] Aprendi a me desnudar, no quarto, após o banho, que havia um frescor sobre a pele e se entranhando nela, [...] que a roupagem abafava e incendiava." (Ibidem, p. 126). Nessa troca com as índias, bem como em toda a sua viagem pelo Brasil, Oribela descortina o novo, o exótico e, quanto mais se abre para o desconhecido, mais "liberta-se de si, do seu passado, do seu modo de ser, hábitos, vícios, convicções, certeza. Pode abrir-se cada vez mais para o desconhecido, à medida que mergulha no desconhecido. No limite, o viajante despoja-se, liberta-se e abre-se.” (IANNI, 1990, p. 16) 
Enfim, quando ocorre uma guerra na fazenda de Francisco, Oribela vê uma nova oportunidade para a fuga. Dessa vez, quem a ajuda é o Ximeno. A órfã, que desde o primeiro encontro é sempre tentada pela imagem do mouro que a espreita “... nos escuros vãos da noite. Muitas vezes eu abria os olhos ainda estava ele, metido dentro de mim e se tinha eu lembrança de um sonho era ele quem me tomava as mãos e levava pelos ares ou vinha a cavalo com vestidos e arreios muito lustrosos..." (MIRANDA, 1996, p. 136) e que, mesmo com esses sonhos românticos, tem pavor dele, suspeitando de que seja a tentação, feitiçaria, mas acaba vencendo suas convicções cristãs, descobrindo um novo mundo, adquirindo conhecimentos e entregando-se amorosamente a ele.

Observa-se, então, que todo o percurso que Oribela fez de Portugal ao Brasil ajudou-a a descobrir-se, a ver a si própria no outro, seja nas índias, seja no mouro. Segundo IANNI, "a História dos povos está atravessada pela viagem... [seja como] modo de descobrir o 'outro', seja como modo de descobrir o 'eu'. É como se a viagem, o viajante e a sua narrativa revelassem todo o tempo [...] o conhecido e o desconhecido, o próximo e o remoto.” (1990, p. $3)$.

Após esse tempo de aprendizado, de reconhecimento de si mesma no outro e de amor pelo mouro, Francisco de Albuquerque consegue recuperá-la e rejubila-se ao vê-la grávida (pois pensa que o filho é seu). Quando a criança nasce (ruiva, isto é, filho do mouro), o português vai embora, levando a criança e abandonando sua mulher. Mas Ximeno consegue resgatar o filho e o traz de volta para sua mãe, que enfim, realiza seu sonho de ser feliz e livre, finalizando sua viagem de busca de identidade, de realização, de encontro e reencontro consigo mesma.

\section{Referências}

DEL PRIORE, Mary. Ao Sul do Corpo: condição feminina, maternidades e mentalidades no Brasil Colônia. Rio de Janeiro: José Olympio; Brasília: EdUnB, 1993.

HUTCHEON, Linda. Poética do pós-modernismo: história, teoria, ficção. Rio de Janeiro: Imago, 1991.

IANNI, Octavio. A metáfora da viagem. Cultura Vozes, São Paulo, v. 90, n. 2, p. 2-19, março/abril. 1990.

MIRANDA, Ana de N. Desmundo. São Paulo: Companhia das Letras, 1996.

PELLEGRINI, Tânia. A ficção brasileira hoje: os caminhos da cidade. UFSC. Revista de 
Crítica Literária Latinoamericana. Año XXVII, n. 53. Lima-Hanover, 1er. Semestre Del 2001, p. 115-128.

SEIXO, Maria Alzira. Poéticas da viagem na literatura. Lisboa: Cosmos, 1998. 